\title{
'I HAVE A CHAMELEON-LIKE EXISTENCE': A DUOETHNOGRAPHIC ACCOUNT OF BORDER CROSSING BY TWO ACADEMIC DEVELOPMENT PRACTITIONERS
}

\author{
S. van Schalkwyk \\ Centre for Health Professions Education \\ Stellenbosch University \\ Stellenbosch, South Africa \\ e-mail: scvs@sun.ac.za
}

\section{W. J. McMillan ${ }^{1}$}

Faculty of Dentistry

University of the Western Cape

Bellville, South Africa

\section{ABSTRACT}

The practice of situating academic development practitioners within faculties poses challenges for practitioners from outside the particular discipline. Literature highlights how discourse and culture create tensions amongst role-players in cross-disciplinary contexts. This duoethnographic account examines the experiences of two practitioners as insider-outsiders in a health sciences disciplinary space. Duoethnography is a collaborative methodology where researchers, in dialogue, critique the meanings they give to social and epistemological constructs. Drawing on border crossing as theoretical lens, the study signals how the insider-outsider location might be mediated to support quality teaching. Border crossing highlights the construct of frontiers and associated identity work. The study identified critical success factors for collaboration - physical presence over time; knowing what is valued; an established identity as scholar and competent practitioner; a community of practice; recognition and an acknowledgement by faculty management; and personal flexibility, sensitivity, approachability and willingness to change.

Keywords: duoethnography, academic development, cross-disciplinary contexts, identity development

\section{INTRODUCTION}

There is a growing recognition of the complexity that characterises the work of academic development (AD) practitioners and their professionalisation (Di Napoli 2014; Saroyan 2014). This recognition is captured in a range of scholarly outputs, some of which highlight how the changing role of the academic holds concomitant implications for the work of AD practitioners (Boud and Brew 2013; Opfer and Pedder 2011). As the move towards professionalisation takes 
root, concerns have been raised about ambiguity regarding the role and position of the AD practitioner (Di Napoli 2014).

A growing trend in South Africa is the placement of AD practitioners in a faculty context rather than, for example, in a central teaching and learning centre and this has added significantly to the complexity described above. The move has been informed by work that emphasises the importance of context in influencing practices around teaching and learning (Debowski 2014). However, a faculty location poses challenges when the practitioner comes with expertise in academic staff development and an interest in the scholarship of teaching and learning, but has no relevant disciplinary background. In this context the new environment, with its particular structure and culture, can present a significant hurdle as practitioners seek to establish their credibility in the disciplinary academic community (Di Napoli 2014). The purpose of this study was to examine the factors that might contribute to achieving acceptance and recognition in different disciplinary contexts. Drawing on 'border crossing' as a theoretical lens, we set out to examine the lived experience of two AD practitioners as insider-outsiders in a particular disciplinary space - that of the health professions.

\section{ACADEMIC DEVELOPMENT RECONCEPTUALISED}

Some exploration of AD as a concept and a practice is necessary before we proceed. The term 'academic development' requires careful definition. While it is often used synonymously with 'faculty development', '(academic) staff development', and 'educational development' (Stes, Min-Leliveld, Gijbels and Van Petegem 2010), in the South African context the term 'academic development' has historical roots in student support and, more recently, student development (Boughey and Niven 2012; Jawitz, Williams, Pym and Cox 2012). The notion of 'development' adds further complexity, as its deficit undertones suggest that those with whom AD practitioners engage are in some way lacking (Land 2001). It is perhaps easiest to define AD in terms of what its intention is. Van Schalkwyk, Leibowitz, Herman and Farmer (2015) suggest that, ultimately, it is about facilitating the professional learning of academics in their teaching role.

Understanding how AD practitioners position themselves in terms of their practice further informs this debate. In his model of AD, Land (2001) highlights an extensive range of functions and positions that can be adopted, and picks up on an agentic role in which the development practitioner influences thinking and impacts on teaching and learning practice. Gosling's report on AD in South Africa (2009) argues, however, that there is a lack of agreement as to its role and function. The report also highlights considerable variance across the system. According to Gosling, representatives from the different AD centres characterised their work in terms ranging 
from 'being an agent of change' to 'adopting a more traditional role of service'.

In addition, there are ongoing calls for practitioners to develop the 'field' of AD by means of a relevant research agenda (Brew 2002; Clegg 2012). Again, Boughey and Niven’s (2012) work is instructive as it explores the mechanisms that have influenced this process in the South African context and the challenges that have been associated with its growth. All of these insights paint a picture of the state of flux and complexity that currently characterises the AD space.

\section{PROFESSIONAL CULTURE AND POWER}

The literature related to cross-disciplinary work highlights how discourse and culture create tensions amongst the various role-players, exposing issues of position, identity and power (Carmichael 2012; Green and Little 2013). The relationship between AD practitioners and health professionals is further complicated by the hierarchical stratification characteristic of the health professions. AD practitioners enter a field which is already marked by issues of power and status, and where the value of different forms of knowledge is contested (Atwal and Caldwell 2005). Green and Little (2013) go so far as describing the relationship between the $\mathrm{AD}$ practitioners and the academics they work with as 'a turf war' which is exacerbated by institutional foci around teaching and learning; this situation may place the AD practitioner in a position that is at loggerheads with their personal understanding of their professional role.

Specific cultural practices structure each profession (Pecukonis, Doyle and Bliss 2008). 'Culture' is a shared body of learned behaviour, and in the health sciences it results in a common set of values, customs, dress, salient symbols, meanings and attributions (Pecukonis et al. 2008). Professional culture determines the distribution of power, and consequently the level and nature of inter-professional communication, as well as the way in which conflicts are resolved and relationships between members of different health professions are managed (Pecukonis et al. 2008). The latter authors offer 'profession-centrism' as a way of explaining how power relations between associated professions develop, operate, and are sustained. Similar to ethnocentrism, profession-centrism is the inclination to view the world from the perspective of the individual's own culture - in this case, the culture which is associated with a particular profession's practice and professional identity (see also Green and Little 2013). The professional thus judges their worth and utility of their own contribution, as well as the worth, utility and potential contribution of others, against a culturally determined set of norms (Pecukonis et al. 2008). This judgement typically results in stereotypical images of the 'other' (Carpenter 1995) and in consequent isolationism, elitism and territorialism (Brand 2003). 
Profession-centrism also results in particular bodies of knowledge being privileged, valued, owned and protected. One of the mechanisms which ensures the autonomy and status of a profession is the way that a domain-specific knowledge-base and associated discourse is developed, codified, maintained and operationalised (Traynor 2009). The 'uniqueness' of the knowledge is also of significance in the establishment and maintenance of professional 'turf'. The effect of the development of profession-centric cultures (with their associated practices, discourses and values) is that some professions come to occupy higher status than others (Atwal and Calwell 2005; Rudland and Mires 2005). This differential status frequently results in professionals from lower-status professions being marginalised, along with their associated knowledge, opinions, and insights (Atwal and Calwell 2005). This marginalisation may be more acute for $\mathrm{AD}$ practitioners entering the field of health sciences, where positivist interpretations are traditionally privileged over more interpretive approaches. There is also a risk that the AD practitioner may endeavour to challenge this marginalisation by adopting a judgemental or moralistic approach towards prevailing discourses.

Evidence suggests that opportunities to work and learn from other professionals have the potential to inform and challenge existing beliefs about those constructed as 'other'. Such collaboration requires willingness to enter into dialogue with another professional (Pecukonis et al. 2008). Contact with other professionals creates familiarity with their associated core values and norms described above, and this familiarity in turn creates credibility for the 'other' profession. Authentic interdisciplinary practice is characterised by an understanding and appreciation of the role and contribution that each professional brings to the problem on hand (Pecukonis et al. 2008). Collaborative practice demands compromise, reconsideration of longheld beliefs and assumptions and the ability to 'hear' the perspectives of others. It is achieved through regular, scheduled, collaborative decision-making activities, project planning, and consultative goal-setting (Pecukonis et al. 2008). In the context of this study, the significant scholarship around health professions education provides an important catalyst for the sort of collaborative work described here.

\section{BORDER CROSSING}

In order to understand the factors that might contribute to achieving acceptance and recognition in the collaborative process of health professions education, we - two AD practitioners who are located within health professions faculties - drew on 'border crossing' as a theoretical lens. 'Border crossing' draws conceptually on the construct of political frontiers and the identity work which people arriving at a border engage in as they cross physical borders (Prokkola 
2009). In the context of this study, the borders were meta-physical, but real nonetheless. We sought to narrate our 'border stories' about these border regions, the barriers and interactions which characterise them and those which have helped to create and sustain our identities (Prokkola 2009).

‘Border crossing identities’ are constructed by those whose lives are threaded with such crossings and through resistance towards unnatural or imposed boundaries (Anzaldua 1987). Sociological and cultural studies emphasise that borders are both material and symbolic, and not only physical or geographical (Lamont and Molnar 2002; Donnan and Wilson 1998). They may, thus, be constituted at the interface between communities, nations, spatial boundaries; through differences in social class, ethnicity/race, and gender/sexuality; and between professions, science, and knowledge (Lamont and Molnar 2002).

The concept of borders, and their associated boundaries, is particularly useful in understanding how professions come to be distinguished from one another (Lamont and Molnar 2002). Two social processes ensure professional boundaries. Firstly, institutional organisation (including aspects such as access, training, credentialing and evaluation of performance) allows professions to draw monopolistic social boundaries against outsiders (Lamont and Molnar 2002). Secondly, scientific knowledge is socially organised. Discipline-specific knowledge is therefore used by professions to position insiders and outsiders, and discursive practices are used to establish epistemic authority (Lamont and Molnar 2002).

Rao, Monin and Durand (2005) offer a conceptual framework which is useful for understanding border work, especially since their framework highlights the way in which power differentials militate against or support border crossing. They suggest that what is important in sustaining borders is not that the 'insider' should conform to all the conventions of the domain all the time, but rather that she must conform to some of the conventions most of the time. This understanding of how border crossing might operate proved to be an important premise for our work.

\section{METHODOLOGY}

\section{Aim and approach}

The aim of this study was to understand our own context and the border work in which we engage in order to identify the factors that contribute to achieving acceptance and recognition in $\mathrm{AD}$ work. Located in faculties of health sciences, and with several years' experience in the field of $\mathrm{AD}$, we were struck by the extent to which our work was valued and our role was 
recognised by our disciplinary colleagues. We perceived our challenges to be somewhat different from those described in the literature and reported by our colleagues in the wider field of $\mathrm{AD}$. We questioned why this might be and considered how a critical enquiry into our quite different narratives might offer insights that would have value for AD practitioners in the future.

We adopted a duoethnographic approach. This poststructuralist methodology represents a collaboration between two researchers who, while engaging in a narrative dialogue around a particular phenomenon, set alongside one another their life histories and perspectives relating to them - this with a view to providing a range of understandings of the matter under review (Norris, Sawyer and Lund 2012). The intention was not to reach consensus, but to offer an interrogation of each other's position while foregrounding one's own, even as new understandings were developed. It sought to emphasise difference through a deeply reflexive process (Latz and Murray 2012). Still a fairly new methodology, duoethnography offers researchers an innovative and alternative space within which to engage in scholarly work, often exploring issues of power and identity (Sameshima 2013). As such, the methodology was wellsuited for our purpose.

Immediately evident from the above discussion is the fact that, with duoethnography, the researchers adopt a different role where they become the site of the research and not the topic, as would be the case in, for example, autoethnography (Norris et al. 2012). It is therefore important that we provide some insights into our personal identities.

\section{Professional profiles of the researchers}

Susan had been working at her university's teaching and learning centre for some years when she was approached to join the health sciences faculty as an educational advisor in a centre for health professions education - this was a result of her building relationships with the faculty during her time at the central unit. A significant portion of her appointment was funded through an external grant, and a core function, over and above her role within the centre, was to lead a large-scale study that would evaluate the implementation of a rural clinical school that has just been established. This project represented a significant investment of finance and resources by the faculty. Susan's work on this project enabled her to immerse herself in health professions education research that, over time, has created traction in terms of her reputation as 'a researcher' within the faculty.

Wendy was initially contracted to a faculty of dentistry, to capacitate academics in terms of their teaching and learning, with a strong emphasis on curriculum design, curriculum alignment and teaching, learning and assessment strategies. Although this later grew into a 
permanent position, at the outset she was employed under conditions of service similar to those of her dental colleagues. Indeed, her post was funded from the Dean's budget for the salaries of clinicians. Over time, her role has shifted and she currently provides a more theoretical basis from which to foster quality teaching and learning. Although the scholarship of teaching has increasingly become one of the aspects of her portfolio, the emphasis of her job description is still related to the development of staff capacity. Both Susan and Wendy have achieved recognition in their faculties as associate professors and more recently as full professors in health professions education. Such recognition is still uncommon in South Africa, particularly for non-medical practitioners.

These short vignettes are simply intended to provide a point of departure for the reader. Ultimately, duoethnography seeks to promote 'complex and inclusive social constructions and re-conceptualisations of experience' rather than to simply tell one's story (Sawyer and Liggett 2012). These constructions and re-conceptualisations, we believe, have value in that they offer a lived yet critically posited new perspective on the phenomenon under investigation.

\section{The iterative process}

In keeping with the principles of the duoethnographic approach, we followed an iterative process that, through a series of dialogues interspersed with individual reflection, led to the generation of our data and its subsequent refinement (analysis) (Norris et al. 2012). At a first meeting, we decided on a focus, namely, the experience of AD practitioners situated within the health sciences and, after a critical reading of the literature, we selected border crossing as a theoretical construct for the study. At our second 'research' meeting we positioned ourselves as critical partners and engaged in detailed discussion of our life stories as AD practitioners.

We freely explored our lived experiences of the phenomenon of border crossing at our two institutions, and adopted the concept of border crossing as our focal point. These narratives were drawn from memory, with our respective recollections often prompting reciprocal reflection in the other partner. In doing so, our 'life writing' (Sameshima 2013) created the 'multi-voiced' texts that characterise the duoethnographic approach. Our dialogic interaction, which lasted approximately 90 minutes, was audio-recorded and subsequently transcribed.

After that, we individually analysed the interview-as-data thematically and jointly juxtaposed our analyses to explore and expose differences in our accounts (Sawyer and Liggett 2012). We then applied the theoretical lens of border crossing, individually preparing a written reflective piece in which we responded to two mutually agreed-upon questions which had emerged through reflection on the transcribed data (see Table 1). Thus the transcribed interview 
and the reflective pieces comprised the data for this study.

Table 1: Two reflective questions, and their associated prompts

\begin{tabular}{|l|l|}
\hline Question & Definition \\
\hline What do I understand the borders to be? & $\begin{array}{l}\text { Nature of border crossing; what are the material and } \\
\text { symbolic indicators? }\end{array}$ \\
\hline $\begin{array}{l}\text { How do I experience and deal with the border, and } \\
\text { with border crossing? }\end{array}$ & $\begin{array}{l}\text { 'being' in that space = symbolic; and material issues } \\
\text { (power, border identity, othering, acceptance, } \\
\text { agency, resistance, theoretical influences, } \\
\text { answerability, purpose of work, community of } \\
\text { practice) }\end{array}$ \\
\hline
\end{tabular}

As a relatively new methodology, there is much in the duoethnographic approach that can be questioned and critiqued. While its intention may be to explore issues of identity, power and position as they exist in the context of the phenomenon under discussion, they are often equally present within the research site itself. There is potential for conflict as, over time, the layers of each researcher's narrative are peeled back, and trust therefore becomes a critical feature of the duoethnographic relationship (Latz and Murray 2012). An equal challenge is that of remaining focused and engaged, while still being able to sufficiently distance oneself from one's own narrative so as to present the final, refined dialogue as formal text (Sawyer and Liggett 2012).

\section{DISCUSSION OF THEMES EMERGING FROM THE PROCESS}

Our analysis foregrounded a set of themes relating to border crossing and these are discussed below.

\section{Understanding the border}

The border was seen as an interface. Susan described it as a 'separation, division, delineation'. For her, the border was characterised by a sense of contrast and otherness, '(A) border exists by virtue of what resides on either side of it, and on either side there is difference'. A border was, she explained, 'a hindrance and a hurdle', intended to 'keep out' the other. Wendy focused less on difference and potential confrontation, suggesting rather that the border might serve as either a 'meeting place ... (or) a dividing line depending on how the encounter happens'. However, differential access to power was explicit in her understanding: 'The border is the space where the ontology and epistemology of "being and becoming a clinician” meets both the space and the imperative of "how to teach" ... which causes awareness of the other. ... Power differentials are implicit at the border.' These power differentials, she explained, were about differential status. She argued that teaching had low status in Western society because it was drawn from the model of mothering which was perceived to be akin to 'common sense'. Thus, 
for her, the border was the 'meeting between people who have high status because they save people from disease and pain' and the other group 'only do what is natural and which has the low status of mother's work'.

The border was shaped, Wendy argued, by both ontology and epistemology, 'There is a significant difference - in that "being the clinician" is ontological whereas "how to teach" is epistemological'. Assumptions about ontology and epistemology also defined how Susan explained what was on either side of the border: '(T)he way people are (their being) on either side of the border and the way people think (their believing) on these two sides'. For her, too, these differences were about 'power and identity'. Just as Wendy argued that encounters at the border could be either positive or negative, Susan emphasised that 'depending on how they play out, ... (they) can be either enabling or constraining'.

\section{Crossing the border}

Susan described crossing the border as an 'act of knowing'. Emphasising the role which volition played in the act, she argued that the crossing required 'a conscious effort - you cannot cross without being aware of the transition'. She felt that it involved risk: '(T)here is safety in remaining on your side of the border. Here everything is familiar, known, intuitive, reassuring.' For Wendy, the risk was more implicit, with her description of the crossing as an 'encounter'. She echoed Susan's sense of border crossing as an active process, associating it with 'awareness of the other'. It is interesting that in their work, Green and Little (2013) talk about the marginal space within which AD practitioners typically work. The perspective that they offer, the 'how to teach', is one of implied conflict and notions of 'colonisation' as the practitioner seeks to make their mark for teaching and learning in the 'other' disciplinary space.

For Susan and Wendy border crossing involved engagement with the spaces on either side of the border and a coming to know. These spaces, according to Susan, 'ultimately define(d) the border'. They were, Wendy explained, 'spaces occupied by ... (differently) defined groups'. Clearly, for both practitioners, these 'spaces' involved specific practices. They described the practices which they perceived as occurring on either side of their borders. Wendy contrasted the practices of clinicians and academic staff developers. She explained that:

(p)eople in this clinical space understand their work as diagnosis, treatment planning, and managing the health of patients and communities. Consequently, they understand themselves as people who do these things. ... Teaching is seen to be 'Watch me while I show you how to do this clinical thing' - the emphasis always being on the 'clinical thing'.

In contrast, she felt that academic developers 'who occupy the space on this side of the border 
seem ... intent on helping university teachers to understand the extent to which what learning is and who students are shapes what students are able to learn and how teachers teach'. Wendy highlighted the potential tension associated with encounters at this border, 'This must be very puzzling for clinicians bent on fixing and maintaining patients and communities, where an assumption seems to be "if I show you what to do", that is sufficient for learning to happen'.

Susan was less explicit about who practises what on each side of the border, although differences in these practices were implicit. She described the various activities that colleagues engaged in and how hierarchy structured her context - and then positioned herself:

People in the faculty position themselves as either academics (most often researchers, although some claim the teaching role more strongly) or clinicians with a teaching and/or research function ... There is a strong hierarchical structure that plays out between the different programmes ... (T)here is much jostling for ascendency, but ... the physician reigns. ... In a sense (there are) a maze of sub-borders that are set up with the 'country'.... In (the centre) ... I am the educationalist (note the word 'the' and not 'a'). ... Thus my crossing over into this space was much more complex than simply moving from one 'country' to another.

While what was on each side of the border emerged as different for Susan and Wendy, both were clear that they were the agents in the border crossing process. This much was implied in Susan's final sentence quoted above. Wendy was more explicit, 'I think the border crossing is done by me. I can’t occupy the "being a clinician” space but I can bring things from my side over to theirs, packed in ways which "match" ontological and epistemological assumptions about being a clinician.' Thus, for Wendy, 'border crossing is what I do when I take things across for the clinicians'.

\section{Early experiences of living on either side of the border}

Early experiences of living on either side of the border were also described quite differently. Wendy came from full time PhD studies into the health sciences - thus her 'other side of the border' was a philosophical meta-place where she had been largely on her own. Her position at the institution established her as a member of staff in the faculty, but the nature of her work meant that she continued to work alone. On the other hand, Susan came from a teaching and learning unit situated at the institution's main campus and her move was both ontological and epistemological - physically locating to a new unit on a different campus attached to a hospital. Thus there was a clear break with her former space. There was a farewell party with a parting gift. At the faculty she became part of a new family of colleagues within the Centre, she got to know when it was someone's birthday, whose child was getting married - it felt like a new home. 
Susan's crossing had been pre-empted by previous short sojourns in the 'other country', which meant that she had become familiar with some of its practices and inhabitants. In addition, she had become discontented with her 'own country', where she had been frustrated by the administrative appointment she held and the restrictions that came with being part of an institutional support service. She felt that in the faculty she 'could challenge the status quo, make a difference, advocate for transformation'.

Both described themselves as initially feeling like migrants in the 'other country' and felt that their presence there was somewhat precarious particularly given the way in which their positions were funded. Wendy said:

(W)hen you've got a twenty-hour contract for a year, you've got a short-term visa. So you really need to like not get caught for drugs, not get caught for speeding, not get caught doing anything wrong.

For both, however, this precariousness changed over time as they moved from a position of migrant to that of citizen. The idea of being migrant has been described previously in the context of AD, but from a different perspective. Green and Little (2013) suggest that the AD practitioner is by definition a 'migrant' having moved from a previous disciplinary space into AD work. In both cases, however, their base disciplines were education, and thus AD work was almost intuitive. The process of changing identities was facilitated by each ones growing awareness of the ways in which knowledge is constructed in this new space, and the positions and ways of thinking that are privileged in the health sciences.

I worked really hard in those initial days to 'market' what an 'Education Advisor' had to offer i.e. how I might add value. I learnt the discourse; I was on the clinical floor weekly. (Wendy)

I have a chameleon-like existence as I endeavour to be part of the team and to understand the people I work with. I use health sciences examples, I read the literature, my writing is generally more clipped. (Susan)

The fact that health professions education had a specific discourse and scholarly tradition meant that they could establish their credibility within an existing field which was recognised on both sides of the border. However, because their roles within the respective faculties were quite different, the ways in which they set down roots was equally different. They both drew on expertise that had been established in the 'own country'. Susan explained:

Ironically, my background in academic literacy and scientific writing has served as the most crucial factor in enabling my entry into this new 'country'. Academic writing and subsequent publishing is the coin of the realm in this context (as indeed in most university structures). For many clinicians, however, writing represents a significant hurdle and one that I now try to help 
them clear. Thus I have become accepted because of what I am seen to bring. (Susan)

\section{Achieving dual citizenship}

Ultimately, they both felt that the metaphor of dual citizenship was a useful one to describe the way in which both sides of the border had become familiar to each of them. This familiarity was reassuring and intuitive, particularly for Susan who, while acknowledging a duality of her existence, appeared to have 'become' a citizen in a more unconscious way than Wendy had. This lack of conscious effort was seen in the extent to which she assimilated the discourse that characterises the health sciences generally - something that was pointed out by Wendy during the analysis discussions conducted as part of this study. Wendy, on the other hand, consciously worked on becoming a citizen in a more material way:

I can't 'be' a clinician - but I have (not necessarily on purpose) taken on some of the more readily available markers of that way of being - for example, dress, discourse, white coat on the clinical floor (I own my own), and a clinical presence (i.e. observation and being in the clinics). (Wendy)

There were other significant differences relating to the way they accepted citizenry of their 'new countries'. Wendy felt strongly that she had two passports and was comfortable with this duality. Susan saw herself as having become a full citizen of the adopted space, and used her former passport less and less. These differences might have had something to do with the way in which they were positioned in their 'new countries'. As mentioned earlier, although Wendy was physically fully integrated into the faculty and the hospital, she was not situated in a unit or department. She was, however, extensively networked regionally with others in health professions education, and these networks formed a community of practice for her work in the faculty. Her relationship with people in the faculty was premised on her work as the person responsible for $\mathrm{AD}$ in teaching and learning. She spoke about 'my staff' - the people she for whom she was responsible and to whom she was accountable. She also noted that people frequently forgot that she was not a medical practitioner.

Susan, on the other hand, took on health professions education as her discipline and a key part of her research focus. Although she continued to feel 'othered', she qualified this 'othering':

I experience this othering in an appreciative way. I have status in the faculty as demonstrated by the way in which I am regularly consulted on a range of issues relating to teaching and learning, and research. (Susan)

Being a citizen on both sides of the border brings with it certain privileges and responsibilities, as citizenship needs to be earned. Both emphasised the need to work hard and build 
relationships in order to establish ourselves. Susan explained: 'I obviously had to work to get this kind of status'. This effort was affirmed by Wendy: 'I believed that I had to work really hard to prove that I was worth having'.

Peseta $(2014,65)$ has called on AD practitioners to assert their agency and 'speak truth to power', maintaining that this is part of their stewardship towards the field. In our experience, responding to this call was enabled as a result of our border crossing. A citizen is allowed to contest the truth of the claims of the country in which she lives. However, this contestation needs to be done with sensitivity. Both of us were involved in a range of faculty structures, with their associated positions of authority. This authority enabled us to make the significant contribution of influencing thinking, policy and practice relating to teaching and learning. Susan summed up the significance of this authority:

With recognition has come agency such that rather than trying to become like the other citizens in the faculty, I feel sufficiently enabled to present my voice and challenge thinking, while remaining mindful of the prevailing culture and dominant discourses. In addition, I have found the new space to be one of considerable 'content' (versus the discontent mentioned earlier). ... I have space to think, to challenge, to try new things. (Susan)

\section{A WAY FORWARD FOR ACADEMIC WORK}

Di Napoli (2014) suggests that exploring how those involved in AD work situate themselves when placed in a context where the institutional and social discourses are at odds with their personal position is an important line of inquiry. We agree, although we acknowledge that our research offers a response from a very specific context - that of the health sciences. For us, a number of key factors emerged that were pivotal in enabling the acquisition of meaningful 'citizenship', as we have described it above. These factors range from the personal and professional to the institutional and political - factors, that Saroyan (2014) has argued, influence the agency of AD practitioners working within complex university systems. They include the need for the entering practitioner to have an established identity, both as a scholar and a competent practitioner; the opportunity for immersion in the new disciplinary environment ontologically, epistemologically and physically - so as to understand what is valued in that context; the establishment of a new network and community of practice that has relevance for the new environment; the importance of an affirming institutional context that includes overt recognition and acknowledgement by senior staff in the faculty, and the need for structures and funding to support the work; and the ability of the practitioner to be flexible, sensitive, approachable and willing to change (Saroyan 2014).

Saroyan (2014) suggests that there are limited opportunities for AD practitioners to own 
a professional identity and yet we found that our agency in the new country was inextricably linked to the extent to which we felt confident and grounded in our AD practitioner identity. Di Napoli $(2014,6,7)$ talks about 'games' that determine the way in which AD practitioners 'enact their values in their own professional contexts ... the political dimension of academic development'. Being able to play the game requires a move away from 'political timidity' (Di Napoli 2014, 8). This insight highlights the need for a focused endeavour for those of us in the $\mathrm{AD}$ community to clearly articulate what $\mathrm{AD}$ is both ontologically and epistemologically, and to do so with conviction and clarity. It further presupposes more than merely a competent practitioner, also requiring dedicated scholarly endeavour in the field (Brew 2002), ultimately leading to an established practitioner with significant power.

There is, however, a latent irony inherent in the call for an established identity. Even as we 'know who we are', the process of immersion, of coming to know and understand the disciplinary discourses at play in the 'new country', of taking up citizenship, all emphasise the need for flexibility. This conspires to reshape our thinking and challenge entrenched positions - leading to a further evolving identity, a richer knowledge base and an extended 'way of doing'.

\section{CONCLUDING COMMENTS}

Land (2001, 10) has described AD practitioners as 'a fragmented tribe, dwelling in many neighbourhoods of a divided village'. This characterisation is not necessarily encouraging and speaks to the issues raised in the opening sections of this article. It also suggests a need for a 'home' for the AD practitioner to counter-act the 'unhomeliness' (Manathunga 2007) that is often experienced as we try to straddle the borders across which we must work. Our study is significant because it signals potential ways in which the placement of AD practitioners in faculties, and the crossing of borders, could be mediated. It highlights how the ethnographic approach, when used in a critical, dialogic manner, can offer opportunities for collaborative colearning. It points to critical success factors that need to be considered, both by the institution and by the individual, when the possibility of placement is being explored, taking us back to the potential of collaboration across disciplinary boundaries to shift thinking and influence change (Pecukonis et al. 2008).

It should, however, also serve as a caution for decision-makers who wish to adopt a decentralised approach to $\mathrm{AD}$ that the practitioners themselves might need mentoring and focused orientation into the new environment to ensure success. Furthermore, there is a risk that as the sense of citizenship takes hold, former identities and the responsibility for being an 
advocate for teaching and learning may fade.

The claims that we make for this research are tempered by our acknowledgement of the limitations of the study. Duoethnography is, by definition, limited to only two perspectives. Our narratives, while different, both refer to rich and enabling experiences for which we are deeply grateful, but which we realise might silence those whose experiences have been different. We recognise that an analysis of less positive experiences would offer further important insights. Nevertheless, we trust that this work will open up conversations within the AD space on this topic. Di Napoli (2014) has posited that if AD practitioners are to be true and effective advocates for a responsive and equitable higher education sector, they will need to mediate like the chameleon - between conflicting discourses and values, while still retaining their authenticity and standing.

\section{ACKNOWLEDGEMENT}

Prof. Wendy McMillan passed away on 23 December 2015, just a few weeks after we received confirmation of the acceptance of the article for publication in this Special Edition. I dedicate this work to a valued and respected colleague, and a dear friend. The nature of this study meant that we shared deeply personal issues over the course of the two years that we were involved in this work and I will miss her very much.

\section{NOTE}

1 Prof. W. J. McMillan passed away in December 2015.

\section{REFERENCES}

Anzaldua, G. 1987. Borderland/ La Frontera: The new mestiza. San Francisco: Aunt Lute Books.

Atwal, A. and K. Caldwell. 2005. Do all health and social care professionals interact equally: A study of interactions in multidisciplinary teams in the United Kingdom. Noric College of Caring Sciences 19: 268-273.

Boud, D. and A. Brew. 2013. Reconceptualising academic work as professional practice: Implications for academic development. International Journal for Academic Development 18(3): 208-221.

Boughey, C. and P. Niven. 2012. The emergence of research in the South African academic development movement. Higher Education Research and Development 31(5): 641653.

Brand, C. 2003. Professionalism: A barrier to provision of quality health care? Archives of Internal Medicine 163(14): 1742-1744.

Brew, A. 2002. Research and the academic developer: A new agenda. The International Journal for Academic Development 7(2): 112-122.

Carmichael, P. 2012. Tribes, territories and threshold concepts: Educational materialisms at work in higher education. Educational Philosophy and Theory 44: 31-42.

Carpenter, J. 1995. Doctors and nurses: Stereotypes and stereotype change in inter-professional education. Journal of Inter-Professional Care 9(2): 151-161. 
Clegg, S. 2012. Conceptualising higher education research and/or academic development as 'fields': A critical analysis. Higher Education Research and Development 31(5): 667- 678.

Debowski, S. 2014. From agents of change to partners in arms: The emerging academic developer role. International Journal for Academic Development 19(1): 50-56.

Di Napoli, R. 2014. Value gaming and political ontology: Between resistance and compliance in academic development. International Journal for Academic Development 19(1): 4-11.

Donnan, H. and T. Wilson. 1999. Borders: Frontiers of identity, nation and state. Oxford: Berg.

Gosling, D. 2009. Report on the survey of directors of academic development in South African Universities. http://www.academia.edu/2233134/Report_on_the_survey_of_directors_of_ Academic_Development_in_South_African_Universities (accessed 3 October 2014).

Green, D. A. and D. Little. 2013. Academic development on the margins. Studies in Higher Education 38(4): 523-537.

Jawitz, J., K. Williams, J. Pym and G. Cox. 2012. Why we do what we do: Interrogating our academic staff development practice. Higher Education Learning and Teaching Association of Southern Africa. In Proceedings of the Higher Education Learning and Teaching Association of Southern Africa (HELTASA) 2012, ed. T. Tisani and M. Madiba. ISBN: 978-0-620-55540-1 Publication date: April 2013.

Lamont, M. and V. Molnar. 2002. The study of boundaries in the social sciences. Annual Review of Sociology 28: 167-195.

Land, R. 2001. Agency, context and change in academic development. International Journal for Academic Development 6(10): 4-20.

Latz, A. O. and J. L. Murray. 2012. A Duoethnography on duoethnography: More than a Book Review. The Qualitative Report 17: 1-8.

Manathunga, C. 2007. Unhomely academic developer identities: More post-colonial explorations. International Journal for Academic Development 12(1): 25-34.

Norris, J., R. D. Sawyer and D. Lund. 2012. Duoethnography: Dialogic methods for social, health, and educational research. Left Coast Press.

Opfer, V. D. and D. Pedder. 2011. Conceptualizing teacher professional learning. Review of Educational Research 81(3): 376-407.

Pecukonis, E., O. Doyle and D. Bliss. 2008. Reducing barriers to inter-professional training: Promoting inter-professional cultural competence. Journal of Inter-professional Care 22(4): 417-428.

Peseta, T. L. 2014. Agency and stewardship in academic development: The problem of speaking truth to power. International Journal for Academic Development 19(1): 65-69.

Prokkola, E. 2009. Unfixing border identity: Border performance and narratives in the construction of self. Journal of Borderlands Studies 24(3): 21-38.

Rao, H., P. Monin and R. Durand. 2005. Border crossing: Bricolage and the erosion of categorical boundaries in French gastronomy. American Sociological Review 60(6): 968-991.

Rudland, J. and G. Mires. 2005. Characteristics of doctors and nurses as perceived by students entering medical school: Implications for shared teaching. Medical Education 39: 448-455.

Sameshima, P. 2013. Duoethnography. Understanding qualitative research and duoethnography: Promoting personal and societal change within dialogic self-study. Journal of the Canadian Association for Curriculum Studies 11: 174-190.

Saroyan, A. 2014. Agency matters: Academic developers' quest and achievements. International Journal of Academic Development 19(1): 57-64.

Sawyer, R. D. and T. Liggett. 2012. Shifting positionalities: A critical discussion of a duoethnographic inquiry of a personal curriculum of post/colonialism. International Journal of Qualitative Methods 11: 628-651.

Stes, A., M. Min-Leliveld, D. Gijbels and P. van Petegem. 2010. The impact of instructional 
development in higher education: The state-of-the-art of the research. Educational Research Review 5: 25-49.

Traynor, M. 2009. Indeterminacy and technicality revisited: How medicine and nursing have responded to the evidence based movement. Sociology of Health and Illness 31(4): 494-507.

Van Schalkwyk, S., B. Leibowitz, N. Herman and J. Farmer. 2015. Reflections on professional learning: Choices, context and culture. Studies in Educational Evaluation 46: 4-10. 